\title{
Making progress to stop tuberculosis
}

\author{
Taylor $\mathbf{G}^{1^{*}}$ \\ ${ }^{1}$ Deputy Chief Public Health Officer, Public Health Agency of Canada, Ottawa, Ontario \\ * Corresponding author: Gregory.Taylor@phac-aspc.gc.ca
}

March 24 is World TB Day - a day to reflect on the current situation of tuberculosis (TB) in Canada and on how we are contributing to the efforts to stop this disease globally.

The good news is that Canada has one of the lowest recorded rates of TB in the world. However, certain populations in Canada continue to be disproportionately affected. Aboriginal peoples and foreign-born individuals who have immigrated to Canada from countries where TB is widespread are at a higher risk of contracting TB than Canadian-born, non-Aboriginal people. Other at-risk populations include the homeless, federal inmates, and persons living with human immunodeficiency virus (HIV). For a summary of TB trends in Canada, see the article in this issue, Tuberculosis in Canada: 1924-2012 (1).

Globally, the news about TB is sobering. TB continues to be one of the most common infectious diseases worldwide. Each year, TB infects almost nine million people and causes more than one million deaths (2). Worldwide, TB is the leading cause of death among people living with HIV. For a disease that is both preventable and curable, this is very disconcerting.

The Stop TB Partnership, hosted by the World Health Organization (WHO), has been working with TB experts and stakeholders from around the world on the Global Plan to Stop TB 2006-2015 (2). The plan identified that globally we have what it takes to bring the TB epidemic to a halt. The plan's strategies include engaging care providers, empowering people with TB, strengthening health systems, and providing high quality treatment, especially for the challenging cases involving co-infection with HIV and multiple drug resistance.

Progress toward global targets for reductions in TB cases and deaths in recent years has been made; TB incidence has started to decline and TB mortality is decreasing (3). The Stop TB Partnership urges all WHO member countries to continue to align their efforts with this plan. I am proud to note that Canada is contributing to the success of the Global Plan. Federal, provincial, and territorial governments, through the Pan-Canadian Public Health Network (PHN) Council, identified 12 essential components of TB prevention and control programs. In 2012, the Public Health Network (PHN) published the Guidance for Tuberculosis Prevention and Control in Canada. The guidance document identifies not only the health system needs for early detection, reporting, and treatment, but also the needs for professional education and community-based awareness and best practices to address social and other determinants of health. For more information, see a summary of this document provided in this issue (4). Since this work was completed, British Columbia (5) and Saskatchewan (6) have released their own strategies for TB prevention and control that align closely with the best practices outlined by the PHN. The Public Health Agency of Canada (the Agency) applauds these initiatives and encourages other provinces and territories to develop their own population-based approaches.

The Agency, in partnership with the Canadian Thoracic Society, has recently released the 7th edition of the Canadian Tuberculosis Standards. This latest edition has been revised extensively. A summary of the changes are highlighted in this issue (7) and includes new diagnostic approaches for both active and latent TB infection, major changes in the treatment recommendations for active, latent, and drug-resistant TB as well as major changes to the treatment recommendations for co-infection with HIV. There is a new approach for contact follow up and outbreak management, as well as a chapter on culturally sensitive programming.

In addition, Canada has contributed to efforts to control TB beyond its borders. TB Reach, funded through a $\$ 120$ million grant from the Government of Canada, is a prime example of Canada's vital partnership role in finding and treating people with TB in some of the world's poorest countries. Canada is also contributing to global efforts through innovative research. New investigation methods, combined with a shift toward prevention models that 
focus on community mobilization rather than on individual behaviour, are showing promising results (8-11). Such pilot projects could have applicability both in Canada and around the world.

Despite all of these initiatives, Canada's work is not done. What is still vitally needed is the ongoing engagement of healthcare providers and the empowerment of people with TB. We must continue to work together locally and nationally in alignment with global partners to address this important issue. The partnerships being developed through the PHN and other federal, provincial, and territorial bodies will go a long way toward achieving our goal as a country and as a champion for improvements to global health.

\section{References}

(1) Gallant V, Ogunnaike-Cooke S, McGuire M. Tuberculosis in Canada - 1924-2012. CCDR 2014;6:99-108.

(2) Stop TB Partnership and World Health Organization. Global Plan to Stop TB 2006- 2015. Geneva, World Health Organization, 2006 (WHO/HTM/STB/2006.35). Available at http://www.stoptb.org/assets/documents/global/plan/GlobalPlanFinal.pdf

(3) World Health Organization. World TB Day, March 24, 2013. Geneva. http://www.who.int/campaigns/tbday/2013/en/

(4) Lord L on behalf of the Public Health Network Council. Summary of the Public Health Network's Guidance for Tuberculosis Prevention and Control Programs in Canada CCDR 2014;6:109-112.

(5) BC Communicable Disease Policy Advisory Committee. BC Strategic Plan for Tuberculosis Prevention, Treatment and Control. 2012. http://www.bccdc.ca/NR/rdonlyres/371821DC-D135-4BC6-8AD94F09CF667B29/0/BC_Strategic_Plan_Tuberculosis.pdf

(6) TB Partnership Working Group. Saskatchewan Provincial Tuberculosis Strategy 2013-2018: Prevention, Treatment, Education and Control. 2013. http://www.health.gov.sk.ca/tb-strategy-pdf

(7) Gale-Rowe M, Menzies R, Sutherland J, Wong T on behalf of the editors and authors. Highlights of the new 7th Edition of the Canadian Tuberculosis Standards. CCDR 2014;6:113-116.

(8) National Lung Framework. Phase II projects: Taima TB and Tuberculosis Education in Aboriginal Youth: An Historical, Socio-Cultural and Public Health Promotional Curriculum. http://www.lunghealthframework.ca/federal-investment/phase-ii-projects

(9) Cook V, Shah L, and Gardy J. Modern contact investigation methods for enhancing tuberculosis control in Aboriginal communities. Int J Circumpolar Health 2012;71:18643. http://dx.doi.org/10.3402/ijch.v7i0.18643

(10) Jensen M, Lau A, Langlois-Klassen D, Boffa J, Manfreda J, and Long R. A population-based study of tuberculosis epidemiology and innovative service delivery in Canada. Int J Tuberc Lung Dis 2012;16(1):43-49. http://www.ncbi.nlm.nih.gov/pubmed/?term=A+population-

based+study+of+tuberculosis+epidemiology+and+innovative+service+delivery+in+Canada

(11) Orr P. Adherence to tuberculosis care in Canadian populations Part 2: a comprehensive approach to fostering adherent behaviour. Int J Circumpolar Health 2012;70(2):128-140. http://www.ncbi.nlm.nih.gov/pubmed/?term=Adherence+to+tuberculosis+care+in+Canadian+populations+ Part+2\%3A+a+comprehensive+approach+to+fostering+adherent+behaviour 